\title{
The Impact of Economic Inequality on Conspiracy Beliefs
}

\author{
Bruno Gabriel Salvador Casara ${ }^{1}$, Caterina Suitner ${ }^{1}$, Jolanda Jetten ${ }^{2}$
}

$$
{ }^{1} \text { University of Padova, Padova, Italy }
$$

${ }^{2}$ University of Queensland, St. Lucia, Brisbane, Queensland, Australia

\section{Author Note}

This research was supported by an Australian Research Council Laureate Fellowship

(FL180100094) awarded to Jolanda Jetten, and by the 2017 PRIN research grant awarded by the Italian Ministry of Education to Anne Maass (2017924L2B). Correspondence concerning this article should be addressed to Bruno Gabriel Salvador Casara, Department of Developmental Psychology and Socialization, University of Padova, Via Venezia 8, 35131 Padova (PD), Italy. Email: brunogabriel.salvadorcasara@phd.unipd.it

Declaration of interest: none

[Accepted for publication in Journal of Experimental Social Psychology] 


\begin{abstract}
Previous literature highlights the crucial role of economic inequality in triggering a range of negative societal outcomes. However, the relationship between economic inequality and the proliferation of conspiracy beliefs remains unexplored. Here, we explore the endorsement of conspiracy beliefs as an outcome of objective country-level (Study 1a, 1b, 1c), perceived (Study 2), and manipulated economic inequality (Studies 3a, 3b, 4a, 4b). In the correlational studies, both objective and perceived economic inequality were associated with greater conspiracy beliefs. In the experiments, participants in the high (compared to the low) inequality condition were more likely to endorse conspiratorial narratives. This effect was fully mediated by anomie (Studies 3a, 3b) suggesting that inequality enhances the perception that society is breaking down (anomie), which in turn increases conspiratorial thinking, possibly in an attempt to regain some sense of order and control. Furthermore, the link between economic inequality and conspiracy beliefs was stronger when participants endorsed a conspiracy worldview (Studies 4a, 4b). Moreover, conspiracy beliefs mediated the effect of the economic inequality manipulation on willingness to engage in collective action aimed at addressing economic inequality. The results show that economic inequality and conspiracy beliefs go hand in hand: economic inequality can cause conspiratorial thinking and conspiracy beliefs can motivate collective action against economic inequality.
\end{abstract}

Keywords: Conspiracy Beliefs, Economic Inequality, Collective Action 


\section{The Impact of Economic Inequality on Conspiracy Beliefs}

Economic inequality (i.e., the unequal distribution of economic resources) is a worldwide concern. Oxfam's 2019 annual report states that in 2019 the world's 2153 richest people owned the same amount of wealth as the poorest 4.6 billion (Coffey et al., 2020). Furthermore, economic inequality is increasing and, according to the Organization for Economic Co-operation and Development (OECD, 2011) income inequality in the OECD countries is at its highest level since 1950. There is growing evidence that economic inequality is not only associated with lower well-being and health (Wilkinson \& Pickett, 2017) but also that the impact of economic inequality is much broader, affecting too the social and political vitality of a society and citizens' socio-political attitudes. For example, economic inequality affects people's political beliefs and preferences (Jetten et al., 2017), and it is associated with lower political participation (Mueller \& Stratmann, 2003; Solt et al., 2011), lower support for democracy (Andersen et al., 2012) and greater endorsement of strong and authoritarian leaders (Sprong et al., 2019). Here we explore the extent to which inequality forms a fertile ground for the proliferation of conspiracy beliefs. We also explore a potential mechanism for this relation. Specifically, we examine whether inequality triggers people's perception that society is breaking down - captured by the sociological concept of anomie (Durkheim, 1897; Messner \& Rosenfeld, 2001; Teymoori et al., 2017). In turn, higher perceived anomie will be associated with gravitation towards conspiracy beliefs because they (rightly or not) hold the promise to restore control and order. We will unpack our reasoning now in greater detail after which we present our empirical studies.

\section{Economic Inequality and Conspiracy Beliefs}

Conspiracy beliefs can be defined as "beliefs about a number of actors who join together in secret agreement and try to achieve a hidden goal which is perceived as unlawful or 
malevolent" (Zonis \& Joseph, 1994, p. 448-449). Beliefs in specific conspiracy theories have been omnipresent, now and throughout history. Consider, for example, conspiracy beliefs which spread in Africa about the Zika and HIV viruses (Klofstad et al., 2019), in the US about 9/11, and in Malaysia about Jews (Swami, 2012). Or think of the spread of beliefs associated with witch hunts during the early modern period, the way that the Nazis prompted and used conspiracy beliefs concerning Jews in Germany (Fay, 2019) and the numerous conspiracies about the origins of the COVID-19 pandemic (Brennen et al., 2020). As evident from the previous examples, conspiracy theories share three main elements. The first common element is that they attribute the real reason for events to powerful actors, e.g., the Illuminati, the New World Order, politicians, multinational companies, drug industries, scientists (Kata, 2010; Swami, 2012; Uscinski et al., 2017). A second element is the belief that actors act to intentionally harm common people. Third, it is thought that such actors plot secretly and hidden from the general public.

A common and robust finding in the literature is that there is often a tendency towards belief in different conspiracy theories, even when they are contradictory (Wood et al., 2012). In order to understand these associations, it has been theorized that there exists a general and stable attitude toward the acceptance of conspiratorial narratives, called a conspiracy worldview (e.g., Dagnall et al., 2015), conspiracist ideation (e.g., Brotherton et al., 2013), or conspiracy mentality (Bruder et al., 2013). Van Prooijen and van Vugt (2018) theorized that this general tendency for believing in conspiracies is the result of evolutionary adaptive processes. According to this adaptive-conspiracism hypothesis, a stronger tendency for believing in conspiracies gave a survival advantage in ancient societies, as people with a stronger tendency to believe in conspiracies were more likely to avoid dangerous hostile coalitions, which were relatively 
common and deadly (West \& Sanders, 2004; Walker \& Bailey, 2013). One of the main advantages of this perspective is that it recognizes interactions between individual differences and environmental factors that trigger conspiracy beliefs. More specifically, when there are environmental cues that trigger it, people holding a stronger conspiracy worldview are more likely to gravitate towards conspiracy beliefs in specific situations. This is consistent with previous evidence showing that conspiratorial cues lead to conspiracy beliefs only when individuals already have a predisposition for conspiracy thought (Uscinski et al., 2016).

Based on this corpus of evidence, we predict that conspiracy beliefs arise when situations or socio-structural conditions trigger psychological needs. Here, we focus on one such sociostructural factor - the perception of economic inequality — and argue that inequality can be an important antecedent for the etiology of conspiracy beliefs among those that endorse a conspiracy worldview more strongly. There are a number of reasons higher economic inequality might trigger conspiratorial thinking. Specifically, inequality provides a fertile ground for conspiratorial thinking to emerge because economic inequality challenges needs which conspiratorial beliefs promise to counter (Douglas et al., 2017). First, conspiracy beliefs may be endorsed when people feel that they lack control. Indeed, a recent meta-analysis (Stojanov \& Halberstadt, 2020) found that a lack of control was associated with greater endorsement of specific conspiracy beliefs. Consistent with compensatory control theorizing (Landau et al., 2015), we propose that a particular stressor to control, economic inequality, may trigger the endorsement of conspiracy beliefs related to the threatening environment as these beliefs provides easy-to-understand explanations of reality.

Second, economic inequality prompts competition and social comparisons and therefore, the need to maintain a positive image of the self and the ingroup (Cheung \& Lucas, 2016; 
Sánchez-Rodríguez et al., 2019). Thus, submitting oneself to conspiracy beliefs may be a way to deal with feelings of insecurity and anxiety that result from economic inequality.

It is important to highlight that we are not arguing that the endorsement of conspiracy beliefs actually satisfies these psychological needs. Rather, such beliefs are attractive for people whose needs have been challenged. In fact, rather than reducing them, conspiracy beliefs have been found to increase uncertainty (Jolley \& Douglas, 2014), decrease a sense of control and autonomy (van Prooijen \& Acker, 2015), and increase distrust toward other people and groups (Einstein \& Glick, 2015). In other words, we argue that conspiracy theories are responses to unsatisfied psychological needs, and it is unclear whether they solve or exacerbate them.

\section{Anomie as a Mediator of the Economic Inequality and Conspiracy Beliefs Relationship}

To explain how economic inequality should affect belief in conspiracy theories, we draw from the sociological concept of anomie. Anomie is defined as a state of society characterized by social dysfunction and chaos in which society provides little moral guidance to its citizens (Durkheim, 1897/1987; see also Teymoori et al., 2017). Consistent with Durkheim's reasoning, Sprong et al. (2019) provided empirical evidence that high levels of economic inequality trigger feelings of anomie. This is because economic inequality not only causes economic instability (Piketty, 2014; Stiglitz, 2012), but also social instability such as is captured by heightened perceptions of anomie (see Jetten et al., 2017). In turn, there are at least two reasons anomie should be associated with a greater belief in conspiracy beliefs. First, anomie has been found to be associated with, on the one hand, withdrawal from and dis-identification with the superordinate group and, on the other hand, with greater attachment to smaller groups that have a greater capacity than larger groups to provide common purpose and a clear self-definition (Teymoori et al., 2017). There is also evidence that, in modern societies, it is typically smaller 
groups such as online communities that advocate for conspiracy beliefs (Samory \& Mitra, 2018) and agreement with such beliefs signals loyalty to group goals (Clark et al., 2019). Second, the primary psychological consequence of anomie is that people perceive that important psychological needs are not satisfied. Indeed anomie is related to a lower sense of personal and collective control and security (Bjarnason, 2009; Hilbert, 1986), reduced perception of meaning in life (Thorlindsson \& Bernburg, 2004), reduced sense of community (Fischer, 1973) and lower self-esteem (Dobson et al., 1979). Consistent with this, there is evidence that, historically, conspiracy beliefs flourish in times of societal crises (van Prooijen \& Douglas, 2017) — contexts that can be defined as being high in anomie.

\section{Conspiracy Beliefs and Collective Action}

Moving a step further, we also explore the possible consequences of endorsement of conspiracy theories on collective action intentions. Previous studies suggest that the perception of economic inequality is associated with a preference for collective action to achieve redistribution of resources (Franko, 2016). However, the literature about the way collective action intentions are related to anomie and conspiracy beliefs shows contradictory findings. Whereas some studies show that higher anomie and conspiracy beliefs are associated with lower civic participation (e.g., Jolley \& Douglas, 2014, Norasakkunkit \& Uchida, 2011) other studies reveal higher collective action intentions (Imhoff et al., 2021; Ionescu et al., 2020; Kim, 2019). However, this contradiction might be more apparent than real and a lack of civic participation may not necessarily reflect lower collective action intentions because societal disengagement can be displayed through collective action (e.g., strike, non-compliance with medical and scientific guidelines, see Lange \& Monscheuer, 2021). It is possible that particularly in the context of high 
economic inequality, collective actions are not an expression of civic participation but should be seen as challenges to the social system.

Indeed, in line, with group-based control theory (Fritsche, 2013; Fritsche, 2017), when people fear they might lose control, they may turn to an agentic in-group in an attempt to obtain control at a collective level. In turn, conspiracy beliefs may be associated with enhanced collective action intentions because conspiracy beliefs are uniquely suited to express willingness to coordinate actions with the ingroup (Pietraszewski et al., 2015), against a powerful outgroup, allowing people to regain a sense of control and meaning through action (Bukowski et al., 2017). That is, conspiracy beliefs, like other ideological beliefs (Clark et al., 2019), communicate dedication to group ideology, and support for the ingroup. Consistent with this, Douglas and colleagues (2019) suggest that conspiracy theories have the power to challenge hierarchies, encourage governments to be more transparent, highlight official versions of events, open new discussions and uncover real conspiracies (Clarke, 2002; Miller, 2002; Swami \& Coles, 2010).

In sum, we argue that perceived economic inequality provides a fertile socio-structural context for a shared perception of anomie, which should, in turn, lead to increased endorsement of conspiracy beliefs. We also explore whether conspiracy beliefs may in turn lead to the challenging of economic elites and whether it may enhance people's willingness to be involved in collective actions aimed at reducing inequality.

\section{The Present Research}

We test the relationship between economic inequality and conspiracy endorsement in eight studies, with different methodologies (correlational and experimental), assessing real or imagined societies and involving different samples. 
In the first set of correlational studies (Study 1a, 1b, and 1c), we tested the relation between economic inequality and conspiracy beliefs at the country-level. Then, in Study 2, we explored the association between subjective economic inequality and conspiracy beliefs at the individual level.

The association between economic inequality and conspiracy beliefs was experimentally tested in Study 3a and 3b, in which we hypothesized that the induced perception of economic inequality causes higher endorsement of conspiracy beliefs. We also provided an initial test of whether this relationship is mediated by anomie.

Moreover, in Study 4a and 4b, we predicted that conspiracy beliefs arise from the interaction between manipulated inequality and more stable individual characteristics such as the extent to which people hold a conspiracy worldview. Specifically, we predicted that economic inequality increases conspiracy beliefs particularly when participants hold a strong conspiracy worldview. Finally, in Study $4 \mathrm{~b}$ we also investigated whether conspiracy beliefs and worldview are positively associated with intentions to address inequality through collective action. In these studies, we report all measures, manipulations and exclusions (see Supplementary Materials). In all studies, sample size was determined before any data analysis.

\section{Study 1a, 1b and 1c}

The goal of these studies was to explore the relationship between objective level economic inequality and conspiracy beliefs.

\section{Method}

In Study 1a, 1b and 1c, we developed a dataset which included (a) data about objective economic inequality as indicated by the Gini index, and (b) endorsement of conspiracy beliefs at the country level. Specifically, in Study 1a we retrieved conspiracy belief scores from a dataset 
including data from 25 countries (see Hornsey et al., 2018). In Study 1b, we retrieved conspiracy belief scores from a dataset including data from 18 countries (see Adam-Troian et al., 2020, Study 2b). Finally, in Study 1c, we retrieved conspiracy belief scores from the YouGovGlobalism Project 2020 - a dataset that includes data from 20 countries. All data analyzed are available at: https://osf.io/vbz2w/?view_only=7277439e36334fc59cc5c94ccd362428, and full datasets are available in the original publications.

\section{Measures}

\section{Economic inequality}

Economic inequality was captured by Gini index estimates provided by the World Bank. The Gini index is a measure of statistical dispersion of income which is widely used to represent economic inequality (e.g., Holland et al., 2009; Nishi et al., 2015; Pickett \& Wilkinson, 2015). Its scores range from 0 to 1 , with higher scores indicating higher economic inequality. In particular, for each study, we used the Gini score matching the year that conspiracy beliefs were measured. Therefore, for Study 1a, we used Gini scores from $2016(M=37.17, S D=6.36)$ and Gini scores from 2020 for Study $1 \mathrm{~b}(M=32.83, S D=6.65)$ and Study $1 \mathrm{c}(M=35.5, S D=6.17)$.

\section{Conspiracy beliefs}

The three studies used different measures of conspiracy beliefs. Specifically, in Study 1a conspiracy beliefs were measured with items from Lewandowsky et al. (2013), which were based on worldwide popular conspiracy theories (i.e., the assassination of President John Kennedy, the death of Princess Diana, the existence of a New World Order, and the 9/11 terrorist attacks) and are rated on 5-point Likert scales ranging from 1 "strongly disagree" to 5 "strongly agree" $(M=3.01 ; S D=0.28)$. 
In Study 1b, conspiracy beliefs were measured using the Conspiracy Mentality Questionnaire (Bruder et al., 2013), which consists of five items (e.g., "events which superficially seem to lack a connection are often the result of secret activities") with responses recorded on an 11-point Likert scale from 1 "0\% completely unlikely" to 11 "100\% completely likely". Finally, in Study 1c, conspiracy beliefs were measured with five items based on worldwide popular conspiracy theories (i.e., a single secret group in charge of the world, global warming, alien contact, origins of the AIDS virus, and the moon landing) rated on 5-point Likert scales with responses ranging from 1 "Definitely false" to 5 "Definitely true".

\section{Results and Discussion}

In all three studies we found a medium positive correlation between Gini and conspiracy belief scores (Study 1a, $r=.35, p=.131$; Study 1b, $r=.40, p=.10$; Study $1 \mathrm{c}, r=.32, p=.17$ ). It should be noted that, given that data were analyzed at the country level, the number of observations were limited. The achieved power was therefore rather low and a post-hoc sensitivity analysis revealed that, given our sample size, with $1-\beta=.80$, we were able to detect only $r>$.46. In order to overcome this limitation and to further test whether these studies collectively support an association between economic inequality and conspiracy beliefs, we conducted a meta-analysis. Consistent with our hypothesis, this meta-analysis revealed that, across the three studies, the Gini score was reliably associated with conspiracy beliefs $(r=.36, p$ $=.009$, see Figure 1). 


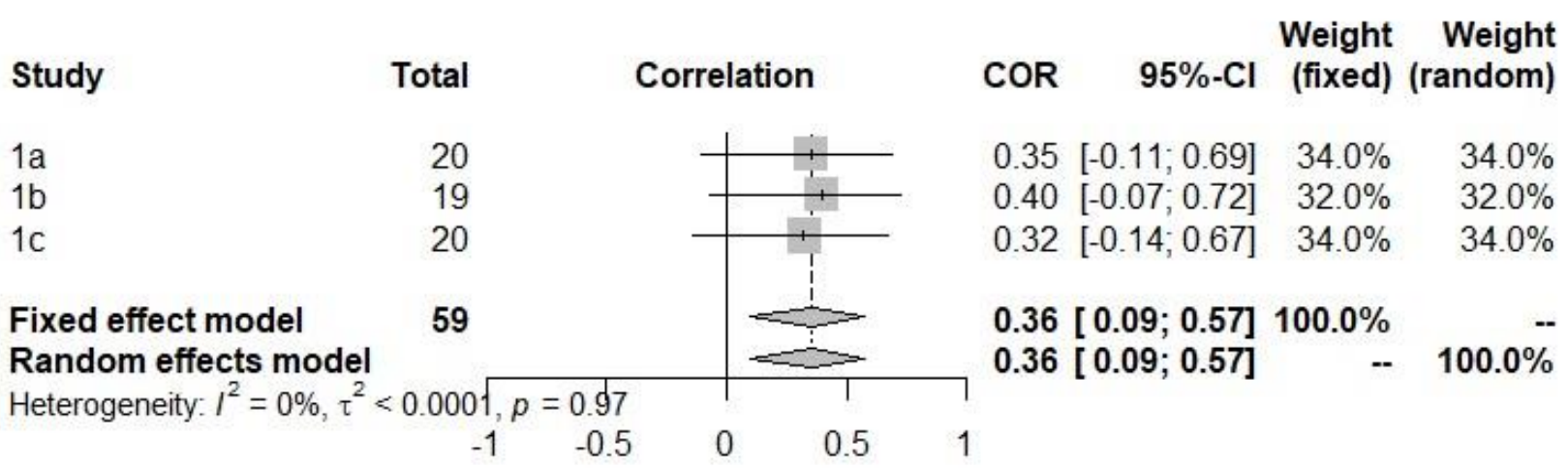

Figure 1. Meta-analysis of the association between economic inequality and conspiracy beliefs.

A closer inspection of the three datasets revealed that, in all three studies, the Gini coefficients for Brazil were outliers and influential cases (scores were higher than 2 standard deviations from the mean, all Cook's distances $>1.49$ ). After eliminating these outliers, Gini scores were reliably and strongly associated with conspiracy beliefs in all three studies (Study 1a, $r=.64, p<.001 ;$ Study 1b, $r=.49, p=.02$; Study 1c, $r=.54, p=.009)$.

In sum, three independent datasets which used different measures of conspiracy beliefs provided initial converging evidence to support the hypothesis that economic inequality is associated with greater endorsement of conspiracy beliefs at the country level.

\section{Study 2}

The goal of Study 2 was to establish the link between perceived economic inequality and the endorsement of conspiracy theories in an Australian context. We also aimed to show that anomie mediates this relationship. Specifically, we predicted that the perception of economic inequality should correlate positively with anomie (H1), which in turn should mediate the association between subjective economic inequality and conspiracy beliefs (H2).

\section{Method}

\section{Participants}


In total, 515 Australian citizens took part in the study ${ }^{1}$. Participation was voluntary and anonymous. Data were collected online via Qualtrics Panels LLC. Participants ranged in age from 19 up to 80 years $(M=43.47, S D=16.41)$, and 263 were women and 252 men. The sample size was determined by financial considerations: Qualtrics charged AU $\$ 11.50$ per participant and our budget allowed for 500 participants. The result of a post-hoc sensitivity power analysis with $N=$ 515 and $1-\beta=.80$ showed that the minimum effect detectable was $r=.11$ for correlations. The study was approved by The University of Queensland Ethics Committee of Psychological Research.

\section{Measures}

\section{Economic inequality}

We measured perceived inequality using the measure reported in Sprong et al. (2019). Participants were presented with a table of five rows showing five wealth categories: "very poor", "poor", "average in wealth", "wealthy", and "very wealthy". They were asked to "think of 100 citizens in their country" and asked "how many of these 100 people would be classified into the different wealth categories." Participants estimated the number of people in each wealth category and wrote the number in a box at the end of each row, with the five estimates adding up to 100 people. The perceived inequality index was calculated in the same way as the calculation of the Gini coefficient. Specifically, four steps were taken to calculate the perceived inequality index (for details see Sprong et al., 2019 Supplementary Materials). In this sample, the perceived inequality index was on average .20 and ranged from .00 to $.36(S D=0.07)$, with higher scores indicating that participants perceived higher levels of inequality in Australia.

\section{Conspiracy beliefs}

\footnotetext{
${ }^{1}$ Study 2 by Sprong and colleagues (2019) draws from the same dataset.
} 
A single item was used to assess conspiracy beliefs among respondents. This item was validated in French and English and its reliability and convergent, discriminant and predictive validity was established in 3 studies with a total of 555 participants (Lantian et al., 2016). The item reads: "Some political and social events are debated (for example: 09/11 attacks, the death of Lady Diana, the assassination of John F. Kennedy). It is suggested that the 'official version' of these events could be an attempt to hide the truth from the public. This 'official version' could mask the fact that these events have been planned and secretly prepared by a covert alliance of powerful individuals or organizations (for example secret services or government). What do you think?" Participants were then asked to indicate to what extent the following sentence represents how they think about this: "I think that the official version of the events given by the authorities very often hides the truth". Responses could range from "completely false" (1) to "completely true" (9). In this sample, the conspiracy beliefs score was on average $6.18(\mathrm{SD}=2.01)$.

\section{Anomie}

Anomie was measured using 12 items each rated on a 7-point Likert scale (Teymoori et al., 2017). The following are four examples of the items: "In Australia today, everyone thinks of him/herself and does not help others in need", "In Australia today, people think that there are no clear moral standards to follow", "In Australia today, the government laws and policies are effective (reverse-coded)" and "In Australia today, the government is legitimate (reversecoded)". Reliability was good $(\alpha=.80)$. In this sample, the level of anomie was on average 4.43 $(S D=0.81)$.

Political orientation, gender, age, education and income 
We also measured political orientation (two items on a scale ranging from "left wing" to "right wing" and from "very liberal" to "very conservative", $r=.57, p<.001, \mathrm{M}=3.99, \mathrm{SD}=$ 1.19), gender, age, education and personal annual income.

Finally, a number of other measures were included in this study (e.g., wish for a strong leader, collective angst) but because they are part of another program of research, they will not be reported here (the full list of variables is reported in the Supplementary Materials). For the secondary analysis of this dataset, only the variables here described were extracted, we did not conduct confirmatory or exploratory analysis on the rest of the dataset.

\section{Results}

In line with H1, correlational analyses confirmed a positive association between perceived economic inequality and conspiracy beliefs, $r=.15, p<.001, C I=[.06, .23]$. This association remained significant even when we controlled for political orientation, gender, age, education and personal annual income (partial $r=.13, p<.001, C I=[.04, .22])$.

Furthermore, in order to test the mediation effect of anomie, we ran a mediation model using the software JASP (Love et al., 2019) with bootstrapping for 5,000 resamples and 95\% confidence intervals (Preacher \& Hayes, 2008). The mediation model confirmed that subjective inequality had an indirect effect via perceptions of anomie on conspiracy beliefs: indirect effect: $b=1.55(S E=0.30), 95 \% \mathrm{CI}=[1,2.19]$. The total effect was fully mediated: direct effect: $b=0.66(S E=0.67), 95 \% \mathrm{CI}=[-0.54,2]$, total effect; $b=2.21(S E=0.63), 95 \% C I=$ $[1.05,3.61]$.

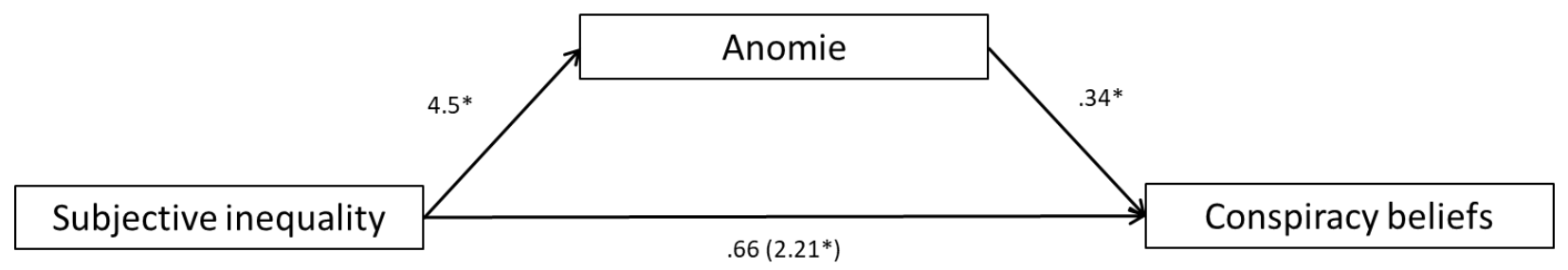


Figure 2. Path model for conspiracy beliefs.

Finally, a multiple linear regression was run to explore whether personal annual income moderated the effect of perceived economic inequality on conspiracy beliefs. The interaction was not significant $(b=-.15, p=.28)$.

\section{Discussion}

The results of this survey supported the hypothesis that the perception of economic inequality (calculated in the same way as the Gini coefficient) is positively associated with conspiracy beliefs in a real-world context. Moreover, this association was fully mediated by anomie.

While the four correlational studies reported so far have good ecological validity, they do not provide evidence that higher inequality causes greater endorsement of conspiracy beliefs. In order to provide evidence for causality, it is necessary to use experimental designs. For this reason, we performed four experiments.

\section{Study 3a}

In this first experiment, we manipulated the perception of inequality using the Bimboola paradigm (Sánchez-Rodríguez et al., 2019; Sprong et al., 2019). This involves an experimental procedure where participants imagine their life in a fictional scenario characterized by high vs. low levels of economic inequality. We predicted that participants assigned to the high inequality condition, compared to the low inequality condition, would report higher levels of conspiracy beliefs (H1) based on the theoretical prediction that the perception of economic inequality triggers psychological needs that conspiracy beliefs promise to address. Moreover, we 
hypothesized that the high inequality condition would increase anomie, which will mediate the effect of the condition on conspiracy beliefs.

\section{Method}

\section{Participants}

A sample of 96 (63 females, 33 males) undergraduate students (age $M=21.11, S D=6.03$ ) were recruited for this experiment, during the same data collection and experiment reported in Study 3a of Sprong and colleagues (2019). Participants were rewarded with course credit. The result of a post-hoc sensitivity power analysis with $N=96$ and $1-\beta=.80$ showed that the minimum effect detectable was $d=.58$ for t-tests, and $\rho=.28$ for correlations. The study was approved by The University of Queensland Ethics Committee of Psychological Research.

\section{Manipulation of Inequality}

The experiment was conducted online. After participants gave their consent to participate, they were asked to imagine that they were going to live in a fictitious society called Bimboola (Sánchez-Rodríguez et al., 2019; Sprong et al., 2019). Participants learned that Bimboola consisted of three income groups and all participants were informed to think of themselves as belonging to the middle-class group which earned 40,000 Bimbolean Coins (BC) per month. Participants were then randomly assigned to one of two possible conditions (high vs. low inequality condition). In the high inequality condition $(N=45)$, the wealthiest group was presented as very wealthy and the poor group as very poor, whereas, in the low inequality condition $(N=51)$, there were no large differences in income among the three groups in Bimboola. Moreover, in order to improve the realism of the procedure, participants had to imagine their life in Bimboola and they were invited to pursue the essentials in life such as a house, mode of transport and holiday. Participants could only choose items that the middle- 
income group could afford and the houses, cars and holidays that they could choose from were identical in the low and high inequality conditions. However, the two experimental conditions manipulated the affordability and availability of items for the poorest and the wealthiest groups.

In the low inequality condition, the houses, cars and holidays available to the poor group were only slightly lower quality than those available to the middle class, and the houses, cars and holidays available to the wealthy group were only slightly higher quality than those available to the middle class. However, in the high inequality condition, compared to the houses, cars and holidays available to the middle class, those available to the poor group were dramatically inferior, e.g., substandard houses, old and damaged motorbikes, no means to go on holiday, and those available to the wealthy group were much more luxurious, e.g., large mansions, top of the range sports cars and expensive holidays.

\section{Measures}

\section{Perceived economic inequality}

Two questions were used as a manipulation check for the perception of economic inequality: "To what extent is Bimboola's economic distribution unequal?" ( $1=$ not unequal at all, 9 = very unequal) and "To what extent is Bimboolean society equal?" ( $1=$ not equal at all, 9 = very equal). Moreover, we checked whether participants correctly recalled which group they had been assigned to using the item "which income level have you been assigned to?"

\section{Conspiracy beliefs}

Conspiracy beliefs were measured using 16 items rated on a Likert scale ranging from 1 (minimum agreement) to 7 (maximum agreement), adapted from Brotherton et al. (2013) (e.g., "New and advanced technology which would hurt current industry is being suppressed", "Certain significant events have been the result of the activity of a small group who secretly 
manipulates world events", "A lot of things get covered up here in Bimboola"; see

Supplementary Materials for the full conspiracy beliefs scale). Given the good reliability ( $\alpha=$ .92), we averaged the items to compute an index of conspiratorial thinking.

\section{Anomie}

As in Study 2, anomie was measured using the same 12 items rated on a 7-point Likert scale $(\alpha=.91)$.

\section{Subjective social class}

Subjective social class was measured on a 10-point scale using 2 items adapted from the MacArthur scale of subjective social status (Adler et al, 2000). Specifically, following the introduction "People at the top of the ladder are those who are the best off, have the most money, most education, and best jobs, whereas people at the bottom of the ladder are those who are the worst off, have the least money, least education, and worst jobs or no job", participants were asked "Where would you place yourself on this ladder relative to others in Australia?" and "How would you classify your own social class background?”.

Finally, a number of other measures were included in this study (e.g., wish for a strong leader) but because they were part of another program of research, they are not reported here. For the secondary analysis of this dataset, only the variables described here were extracted and we did not conduct confirmatory or exploratory analysis on the rest of the dataset (the full list of variables is available in the Supplementary Materials).

\section{Results}

\section{Manipulation check}

A t-test confirmed that participants in the high inequality condition perceived higher levels of economic inequality in Bimboolean society $(M=5.43, S D=1.75), t(95)=5.4 ; p<$ 
$.001 ; d=1.1$, and lower levels of economic equality $(M=2.29, S D=1.38), t(95)=-6.55, p<$ $.001 ; d=-1.33$, compared with those in the low inequality condition $(M=3.71, S D=1.33 ; M=$ $4.11, S D=1.37$, respectively).

\section{Conspiracy beliefs}

Supporting H1, a t-test confirmed that participants in the high inequality condition were more likely to endorse conspiracies $(M=4.11, S D=.87)$ compared to those in the low inequality condition $(M=3.3, S D=1.04), t(95)=7.52, p<.001 ; d=.8)$.

\section{Mediation analysis}

Similar to Study 2, we examined whether anomie mediated the relationship between manipulated levels of inequality and conspiracy beliefs. The mediation model confirmed that the economic inequality condition had an indirect effect via perceptions of anomie on conspiracy beliefs: indirect effect: $b=.43(S E=0.13), 95 \% \mathrm{CI}=[.17, .76]$. The total effect was fully mediated: direct effect: $b=0.33(S E=0.20), 95 \% \mathrm{CI}=[-0.90, .83]$; total effect; $b=0.76(S E=$ $0.19), 95 \% C I=[0.40,1.14]$.

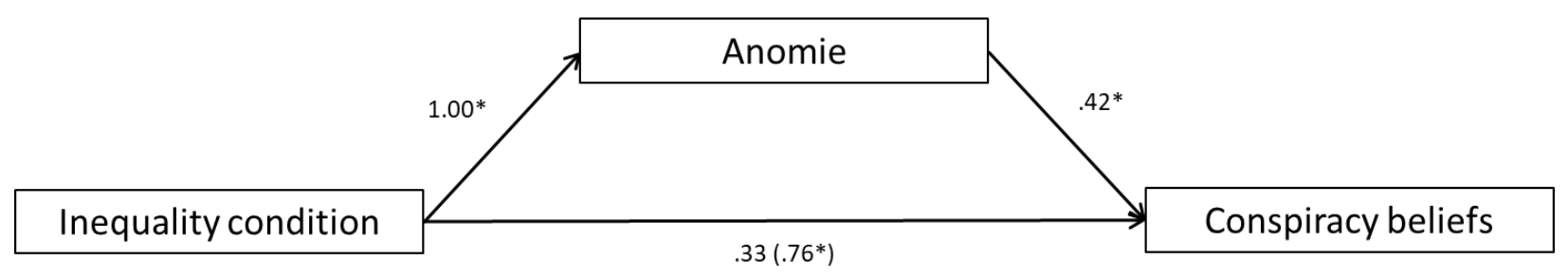

Figure 3. Path model for conspiracy beliefs.

Again, a multiple linear regression was run to explore whether personal annual income moderated the effect of perceived economic inequality on conspiracy beliefs. The interaction was not significant $(b=-.28, p=.32)$.

\section{Discussion}


As expected, the high (vs. low) economic inequality condition led to higher endorsement of conspiracy beliefs about the fictitious society of Bimboola via anomie. Nonetheless, our sample was small and despite the fact that we found strong effects, the effect size may have been overestimated by the limited sample size (Levine et al., 2009). In order to overcome this limitation, we conducted another study that was sufficiently powered.

\section{Study 3b}

The aim of this study was to replicate the result found in the previous study, and therefore, confirm the hypothesized causal relationship between the perception of economic inequality and conspiracy beliefs (H1), and to confirm the mediating role of anomie (H2), using a larger sample and involving a different population.

\section{Method}

\section{Participants}

Data were collected online via MTurk from a sample of 296 US residents, during the same data collection reported in Study 3b by Sprong and colleagues (2019). Participants' age ranged from 23 to 80 years $(M=41.53, S D=11.11)$, and the sample included 161 women and 135 men. The result of a post-hoc sensitivity power analysis with $N=100$ and $1-\beta=.80$ showed that the minimum effect detectable was $d=.32$ for t-tests.

\section{Measures and Procedure}

The procedure was identical to Study 3a. Specifically, Study 3b incorporated the same manipulation of economic inequality and the same dependent measures as used in Study 3a (see the Supplementary Materials for a full overview of measures). Again, the reliability of the conspiracy belief and anomie measures was high $(\alpha=.97 ; \alpha=.96)$.

\section{Results}




\section{Manipulation check}

A t-test confirmed that participants in the high inequality condition perceived higher levels of economic inequality in Bimboolean society $(M=6.5, S D=.92), t(294)=30.17 ; p<$ $.001 ; d=3.50$, and lower levels of economic equality $(M=1.66, S D=1.03), t(95)=-25.45, p<$ $.001 ; d=-2.96$, compared with those in the low inequality condition $(M=2.94, S D=1.10 ; M=$ 4.89, $S D=1.03$, respectively).

\section{Conspiracy beliefs}

Supporting H1, a t-test confirmed that participants in the high inequality condition were more likely to endorse conspiracies $(M=4.01, S D=1.3)$ compared to those in the low inequality condition $(M=2.60, S D=1.30), t(294)=10.00, p<.001 ; d=1.16)$.

\section{Mediation analysis}

We again examined whether anomie mediated the relation between manipulated levels of inequality and conspiracy beliefs. The mediation model confirmed that economic inequality condition had an indirect effect via perceptions of anomie on conspiracy beliefs: indirect effect: $b=1.09(S E=0.10), 95 \% \mathrm{CI}=[.88,1.31]$. The total effect was fully mediated: direct effect: $b=-0.08(S E=0.12), 95 \% \mathrm{CI}=[-0.31, .14]$; total effect; $b=1.00(S E=0.10), 95 \% C I=$ $[0.80,1.20]$

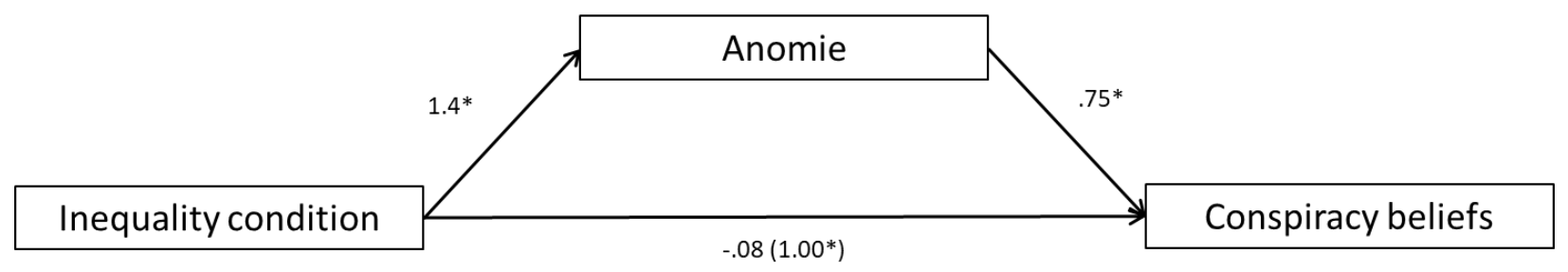

Figure 4. Path model for conspiracy beliefs.

\section{Subjective social class interaction}


A multiple linear regression was run to explore whether personal annual income moderated the effect of perceived economic inequality on conspiracy beliefs. The interaction was not significant $(b=.24, p=.16)$.

\section{Discussion}

The results of Study $3 \mathrm{~b}$ replicate the results of Study 3a, confirming once again that the perception of economic inequality has a strong effect on conspiracy beliefs. The strong effects found in Studies 3a and 3b provide the first evidence that socio-structural factors such as economic inequality cause and increase conspiracy beliefs. Furthermore, we again confirmed the mediating role of anomie suggesting that economic inequality prompts conspiracy beliefs because inequality enhances the perception that society is breaking down (both its leadership and its social fabric) and such increased anomie then triggers a search for meaning and control which conspiracy beliefs promise to provide.

However, there is robust evidence that people holding conspiracy beliefs hold a more general conspiracy worldview which is highly predictive of conspiracy beliefs (Uscinski et al., 2016). Based on the adaptive-conspiracism hypothesis (van Prooijen \& van Vugt, 2018), the attribution of conspiracies to a situation or a context is the result of environmental cues and individual preferences toward conspiracy narratives. For this reason, in Studies $4 \mathrm{a}$ and $4 \mathrm{~b}$, we tested the potentially moderating role of the individual difference variable, conspiracy worldview, in the relationship between inequality and the endorsement of contextually specific conspiracy beliefs.

\section{Study 4a}

In Study 4a, we used a simplified version of the Bimboola paradigm, and we measured belief in conspiracies using four new items. The use of a different and simpler experimental 
manipulation provides the advantage that it conceptually replicates the results of the previously described studies using a different experimental procedure, thereby testing the conceptual generalizability of our findings. Moreover, it involves another population, namely Italian students, testing the cross-cultural generalizability of the findings.

Once again, we expected that imagining living in a society in which there is high economic inequality enhances the belief in conspiracies (H1). Moreover, in line with van Prooijen and van Vugt (2018), we argue that in addition to contextual factors (such as economic inequality), more stable individual characteristics such as the extent to which people hold a conspiracy worldview predict the endorsement of specific conspiracy beliefs. Conspiracy worldview is here operationalized as a general and relatively stable attitude tapping the perceived prevalence of conspiracies in the real world (Albarracin \& Shavitt, 2018). We therefore expected that people with higher levels of conspiracy worldview should be more sensitive to processes triggered by economic inequality $(\mathrm{H} 3)$, strengthening the relationship between inequality and the endorsement of specific conspiracy beliefs.

\section{Method}

\section{Participants}

The experiment was conducted online using Qualtrics survey software. Sixty-four Italian psychology students completed the experiment. Eight participants failed the manipulation check and were excluded. The final sample consisted of 56 participants $\left(M_{\text {age }}=20.75 ; S D_{\text {age }}=2.96\right)$. The result of a post-hoc sensitivity power analysis with $N=56$ and $1-\beta=.80$ showed that the minimum effect detectable was $d=.76$ for t-tests and $f^{2}=.21$ for regressions. The study was approved by the Padua Ethics Committee of Psychological Research.

\section{Procedure}


In this study, we used a simplified version of the Bimboola paradigm. After reading the informed consent and agreeing to participate, participants were randomly assigned to one of two experimental conditions. Participants were shown a short text describing the fictional Western society of Kalo. In both conditions they were asked to imagine their life in this new society. In the high (vs. low) inequality condition, Kalo was characterized as a society with a high (vs. low) wage gap between business owners-managers and workers, with an economy based on few multinational companies' activity (vs. based on several small and medium companies' activity), and as having a flat (vs. progressive) tax rate. We included a two-item manipulation check assessing the perceived economic inequality in Kalo ("There are strong wealth differences between the managerial and the working class in Kalo"; "The wealth differences among Kalo's citizens are small"; $r=.92$ ). Participants were excluded when they answered these items inconsistently (e.g., marking "Totally agree" to both the questions). Furthermore, because the manipulation states that managers earn one hundred times more than the workers, participants were also excluded if when answering the first of these manipulation checks they gave a response lower than 51, on a scale ranging from 0 ("Totally disagree") to 100 ("Totally agree"). After that, participants were presented with items related to conspiracy beliefs in Kalo and they were asked to indicate the extent to which democracy, interpersonal trust, ecologism, and religiosity are features of Kalo's society. The order of these items was randomized. Finally, participants were asked to complete a conspiracy worldview scale, and to indicate their political orientation, sex, age and education.

\section{Conspiracy beliefs}

Conspiracy beliefs were operationalized as beliefs about powerful groups acting in secret in order to achieve their goals even when they are deliberately harmful for the population of 
Kalo. Participants were asked to indicate the extent to which they agreed with the following four items on a scale ranging from 0 (minimum agreement) to 100 (maximum agreement): "Politicians of Kalo aim to maintain their power and pursue their interests even when this deliberately harms the rest of the population"; "In Kalo society, the pharmaceutical industry aims to meet their economic and political goals, even when they are aware that their actions will harm citizens"; "Multinational companies secretly and deliberately exploit the workers and the resources of Kalo's society in order to increase their profit"; "Scientists in Kalo fabricate or exaggerate several issues in order to maintain their social status, even when they are aware that their actions have dramatic negative effect for the citizens" $(\alpha=.89$; inter-item correlation $=.67)$. Given the good reliability and inter-item correlation, we averaged the items to compute an index of conspiracy beliefs.

\section{Conspiracy worldview}

One question, closely aligned to the one-item measure validated by Lantian and colleagues (2016), assessed a general conspiracy worldview: "In the world, powerful groups secretly act in order to achieve their goals, even if they are aware that their plans will harm the rest of the population". Responses to this question were recorded on a scale ranging from 0 (almost never) to 100 (very frequently).

Finally, assumptions toward Kalo's society assets, political orientation, education and age were not relevant for this line of research and therefore will not be reported here.

\section{Results}

\section{Manipulation check}

A t-test confirmed that participants in the high inequality condition perceived a higher wage gap between the managerial and working class $(M=93.73, S D=11.11), t(41.85)=8.95 ; p$ 
$<.001 ; d=2.342$, and among citizens $(M=89.58, S D=14.84), t(51.39)=7.94, p<.001 ; d=$ 2.10, than did those in the low inequality condition $(M=49.47, S D=24.30 ; M=50.57, S D=$ 21.70 , respectively).

\section{Conspiracy beliefs}

A t-test confirmed that participants in the high inequality condition were more likely to endorse conspiracies $(M=65.89, S D=12.27)$ compared to those in the low inequality condition $(M=39.37, S D=13.95), t(54)=7.52, p<.001 ; d=2$. Given that multinational companies and pharmaceutical industries are part of the economic elites, and because they are often the focus of conspiracy theories, we checked whether the effect of our experimental manipulation on conspiracy beliefs was driven by inclusion of these items. Because similar results were obtained when only items were included that did not refer to multinational and pharmaceutical industries, $t(54)=7.53, p<.001 ; d=2.02)$, we decided not to omit these two items from our analyses.

\section{Conspiracy worldview}

Responses on items assessing conspiracy worldview did not differ between conditions $\left.\left(M_{H I}=63.58, S D_{H I}=16.83 ; M_{L I}=70.23, S D_{L I}=19.08\right), t(54)=-1.39, p=.171 ; d=-.37\right)$, providing reassurance that randomization had been successful.

\section{Conspiracy worldview as moderator}

We conducted a multiple linear regression to test whether conspiracy worldview moderated the effect of economic inequality on conspiracy beliefs. The result was in line with $\mathrm{H} 2$; the higher the conspiracy worldview, the stronger the effect of high vs. low inequality on conspiracy beliefs (Figure 5). However, even though the interaction was statistically significant and in the predicted direction, the single slopes for the high economic inequality condition $(\beta=$ $.27, p=.09)$, and the low economic inequality condition $(\beta=-.19, p=.12)$ were not statistically 
significant. However, there was a main effect of economic inequality on conspiracy beliefs for participants with low $(-1 S D, t(52)=3.89, p<.001)$ or high $(+1 S D, t(52)=6.88, p<.001)$ levels of conspiracy worldview.

Moreover, based on the Bayes Factor, the model including conspiracy worldview as moderator is the preferred model compared with the model including experimental conditions and conspiracy worldview as independent predictors $(\mathrm{BF}=3.20)$. However, this model was equal in predictive power compared to the model including only experimental condition as a predictor $(\mathrm{BF}=0.83)$.

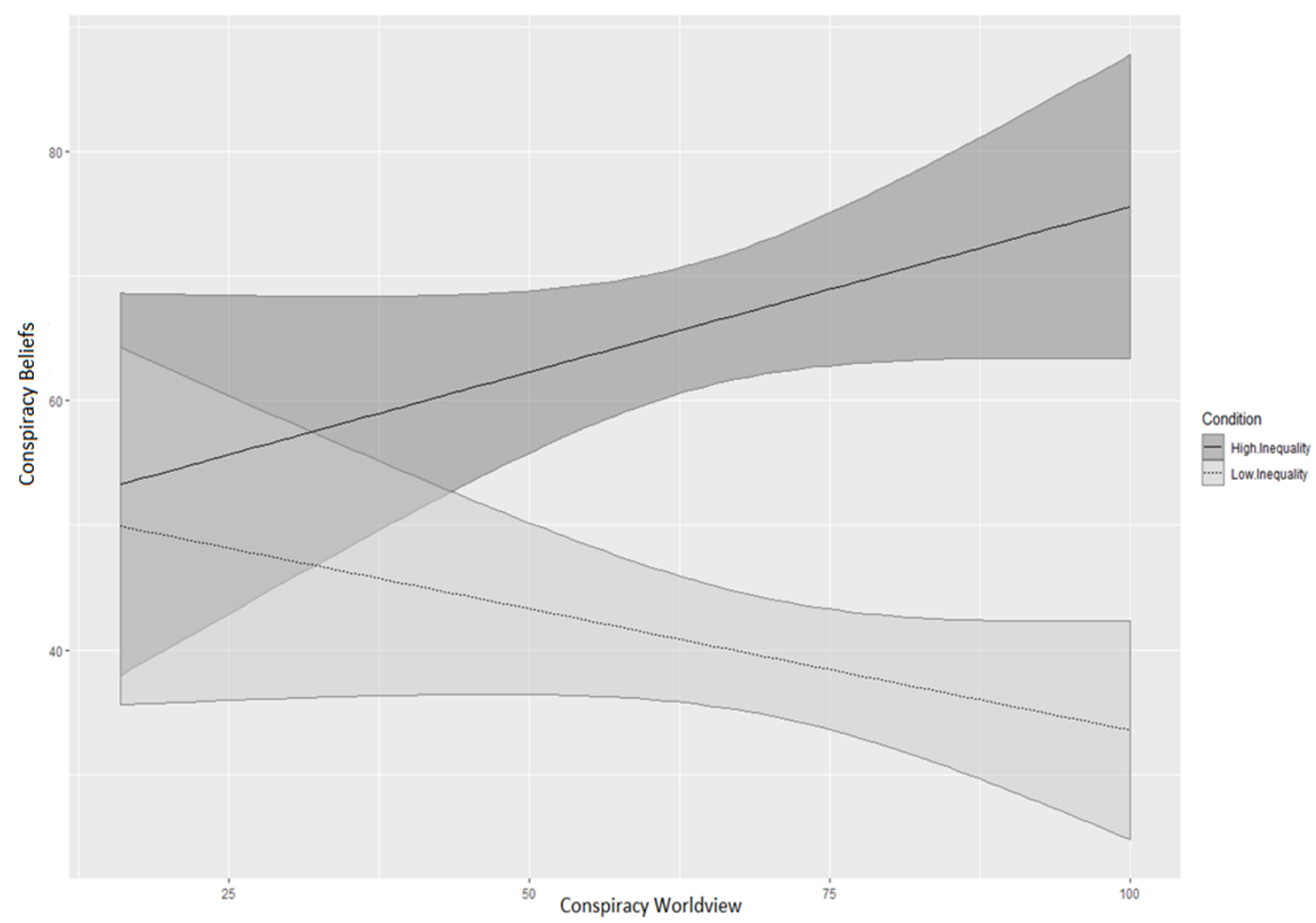


Figure 5. Interaction plot of conspiracy beliefs by conspiracy worldview for high inequality and low inequality conditions.

\section{Discussion}

As expected, the high (vs. low) economic inequality condition led to higher endorsement of conspiracy beliefs about the society of Kalo (H1). The results of this study were in line with Studies $3 \mathrm{a}$ and $3 \mathrm{~b}$, showing a strong effect of the perception of economic inequality on conspiracy beliefs. Moreover, manipulated inequality did not affect all participants in the same way. Participants with stronger conspiracy worldview were more sensitive to the high inequality manipulation in comparison with the low inequality manipulation, supporting the notion that conspiracy beliefs arise as a result of an interaction between a conspiracy-detector system and socio-structural factors.

However, despite the fact that we corroborated the findings of previous studies and we found strong effects for most of our hypotheses, the slopes did not reach acceptable levels of significance in the moderation analysis. In particular, we did not find that conspiracy beliefs were associated with conspiracy worldview in the high inequality condition. Even though the interaction was significant and in the expected direction, the Bayes Factor did not provide evidence in favor or against the interaction. Therefore, we ran a final pre-registered study whereby the sample size was decided on the basis of an a priori power analysis.

\section{Study $4 b$}

The aim of Study $4 \mathrm{~b}$ was twofold: (a) to replicate the results of Study 4a and (b) to explore the link between conspiracy beliefs and collective action intentions to combat economic inequality. This study was preregistered on OSF (https://osf.io/pa3t7/?view_only=c8e8afdbf7e44f648e9e8812728c0c27). 
Specifically, we tested whether involving participants in a fictitious society characterized by high (vs. low) economic inequality would enhance conspiracy beliefs in that context and whether this, in turn, would mediate enhanced collective action intentions aimed at reducing economic inequality. Moreover, going beyond the fictional scenario, we tested if a broader conspiracy worldview would be associated with general collective action intentions against economic inequality.

In line with pre-registered hypotheses (https://osf.io/vbz2w/?view_only=f94f8dbd202041119614b5a52b5685c3), we predicted that participants in the high (compared to low) economic inequality condition would be more likely to endorse conspiracy beliefs in the context of the fictional scenario (H1) and that the effect of experimental conditions would be moderated by participants' conspiracy worldview (H3).

New hypotheses about the role of conspiracy beliefs in collective action intentions aimed at reducing economic inequalities were included in an exploratory fashion. Specifically, we tested whether involving participants in a fictitious society characterized by high (vs. low) economic inequality would increase conspiratorial thinking and whether this, in turn, mediated collective action intentions aimed at reducing economic inequality. Moreover, we hypothesized that conspiracy beliefs about Kalo should mediate the effect of the economic inequality manipulation on support for collective actions aimed at improving Kalo's society (H4a). We also expected this association not to be limited to the fictional scenario and thus, we expected to find a similar association toward conspiracy worldview and intentions to participate in collective actions (e.g., signing a petition) aimed at reducing economic inequality (H4b). In order to explore if the association between conspiracy worldview and willingness to engage in collective actions is generalizable to other social issues, we tested the association between conspiracy 
worldview and intention to participate in collective actions aimed at i) reducing gender inequality (an issue that is usually related to a left-wing agenda; Evans, 1993), and ii) aimed at reducing illegal immigration (an issue usually related to a right-wing agenda; Diamond, 1996).

Finally, a number of other measures were included in this study (e.g., political orientation, populism, assumptions toward Kalo's society assets) but because they are part of another program of research they will not be reported here.

\section{Method}

\section{Participants}

Based on an a priori power analysis aimed at detecting an effect size in a monodirectional t-test of at least $d=.5$, with $1-\beta=.80$, and $\alpha=.05$, we administered an online questionnaire among 104 Italian participants who were recruited via social media (e.g., Facebook, LinkedIn). Nine participants were excluded as they failed the manipulation check (see pre-registered procedure). The final sample consisted of 95 Italian participants $\left(M_{\text {age }}=30.12\right.$; $\left.S D_{\text {age }}=12.6\right)$. The study was approved by the Padua Ethics Committee of Psychological Research.

\section{Measures and Procedure}

The procedure was identical to Study 4a. Specifically, Study $4 \mathrm{~b}$ incorporated the same manipulation task, stimuli and measures as used in Study $4 \mathrm{a}^{2}$. Again, the reliability index of the conspiracy measure was good $(\alpha=.84)$. We included the additional measures described below in order to test the new hypotheses.

\section{Situational collective action intentions}

\footnotetext{
${ }^{2}$ The procedure and measures were shown to participants with the following order: 1. Experimental conditions (high vs. low inequality); 2. Manipulation check (2 items); 3. Conspiracy beliefs and evaluation of Kalo's assets (8 items); 4. Situational collective action intentions; 5. Conspiracy worldview; 6. General collective action intention; 7. Populism; 8. Political orientation, age, gender, education.
} 
Participants responded to 10 items asking them to rate their agreement to engage in collective action aimed at improving the society of Kalo. Agreement with these statements was indicated on a scale ranging from 0 (minimum agreement) to 100 (maximum agreement). The reliability of these items was not high $(\alpha=.59)$, therefore, we ran an explorative factor analysis, where parallel analysis was used as the extraction method, and promax was used as the rotation method. We found a three-factor solution which explained $47 \%$ of the variance. Two items ("To make it a better society, Kalo's citizens should engage in collective protests calling for a reduction in the duration of compulsory schooling/training so students can be free to stop their education whenever they want", "To make Kalo a better society, I would engage in collective protests asking for weaker government regulation of the economy") were eliminated because they did not contribute to a simple factor structure.

Factor 1 was related to support for Kalo's welfare policies (such as increased compulsory schooling years, the implementation of a wage cap, the implementation of a minimum wage, support for state interventions in the economy) and it comprised four items (e.g., "To improve the society of Kalo, citizens should protest for the implementation of a minimum wage", "To make Kalo a better society, I would engage in collective protests asking for stronger government regulation of the economy") that explained 32\% of the factor variance with factor loadings ranging from .432 to .692 . Factor 2 was related to support for charity and it comprised two items (e.g., "To improve the society of Kalo, I would organize a charity fundraiser") that explained $81 \%$ of the factor variance. Finally, Factor 3 was related to tax compliance and it comprised two items (e.g., "To improve the society of Kalo, I would advocate for higher taxation to enable the Government to implement better social welfare policies") that explained $48 \%$ of the factor variance. 


\section{General collective action intentions}

Participants responded to nine statements adapted from van Zomeren and colleagues' (2010) measures aimed at assessing general behavioral intentions to engage in collective actions to counter economic inequality $(\alpha=.85)$, gender inequality $(\alpha=.93)$, and illegal immigration $(\alpha$ $=.94$ ) (e.g., "I would sign a petition in order to support measures against economic inequality", "I would vote for a political party that fights gender inequality", "I would like to participate in collective action in order to fight illegal immigration").

Finally, a number of other measures were included in this study (political orientation, assumptions about Kalo's society assets, populism, age, education) but because these are part of another program of research, they will not be reported here.

\section{Results}

\section{Manipulation check}

A t-test (with Welch's correction) confirmed that participants in the high inequality condition perceived a higher wage gap between the managerial and working-class $(M=97.24$, $S D=7.13), t(42.57)=12.53 ; p<.001 ; d=2.77$, and among citizens $(M=91.78, S D=18.48)$, $t(67)=12.08, p<.001 ; d=2.57$, compared with the low inequality condition $(M=39.5, S D=$ $28.50 ; M=34.2, S D=25.70$, respectively), confirming the success of the economic inequality manipulation.

\section{Conspiracy beliefs}

In line with $\mathrm{H} 1$, a t-test confirmed that participants in the high inequality condition were more likely to endorse conspiracy theories in Kalo $(M=66.24, S D=18.19)$, compared to those in the low inequality condition $(M=37.13 ; S D=21.40), t(93)=7.15, p<.001 ; d=1.50$. Similar 
results were obtained when the items referring to multinational and pharmaceutical industries were excluded from the scale, $t(93)=9.14, p<.001 ; d=1.90$.

\section{Conspiracy worldview}

Responses on conspiracy worldview did not differ between conditions $\left(M_{H I}=77.00, S D_{H I}\right.$ $\left.\left.=18.15 ; M_{L I}=68.08, S D_{L I}=27.85\right), t(62.51)=-1.77, p=.08 ; d=.38\right)$, providing reassurance that randomization had been successful.

\section{Conspiracy worldview as moderator}

In order to test the moderation effect of conspiracy worldview we computed a multiple linear model. The result was in line with $\mathrm{H} 2$; the higher the conspiracy worldview, the stronger the differences in conspiracy beliefs in the high versus low inequality condition (Figure 6). Moreover, based on the Bayes Factor, the model including conspiracy worldview as moderator was preferred both compared to the model including only experimental condition as predictor $(\mathrm{BF}=9.25)$, and compared to the model including experimental condition and conspiracy worldview as independent predictors $(\mathrm{BF}=13.68)$. Specifically, while the single slope for the high economic inequality condition was statistically significant $(\beta=.46, p=.002)$, it was not significant for the low economic inequality condition $(\beta=-.08, p=.48)$. Finally, there was a main effect of economic inequality on conspiracy beliefs for participants with both low (-1SD, $t(91)=2.70, \mathrm{p}=.008)$ and high $(+1 S D, t(91)=7.13, p<.001)$ levels of conspiracy worldview. 


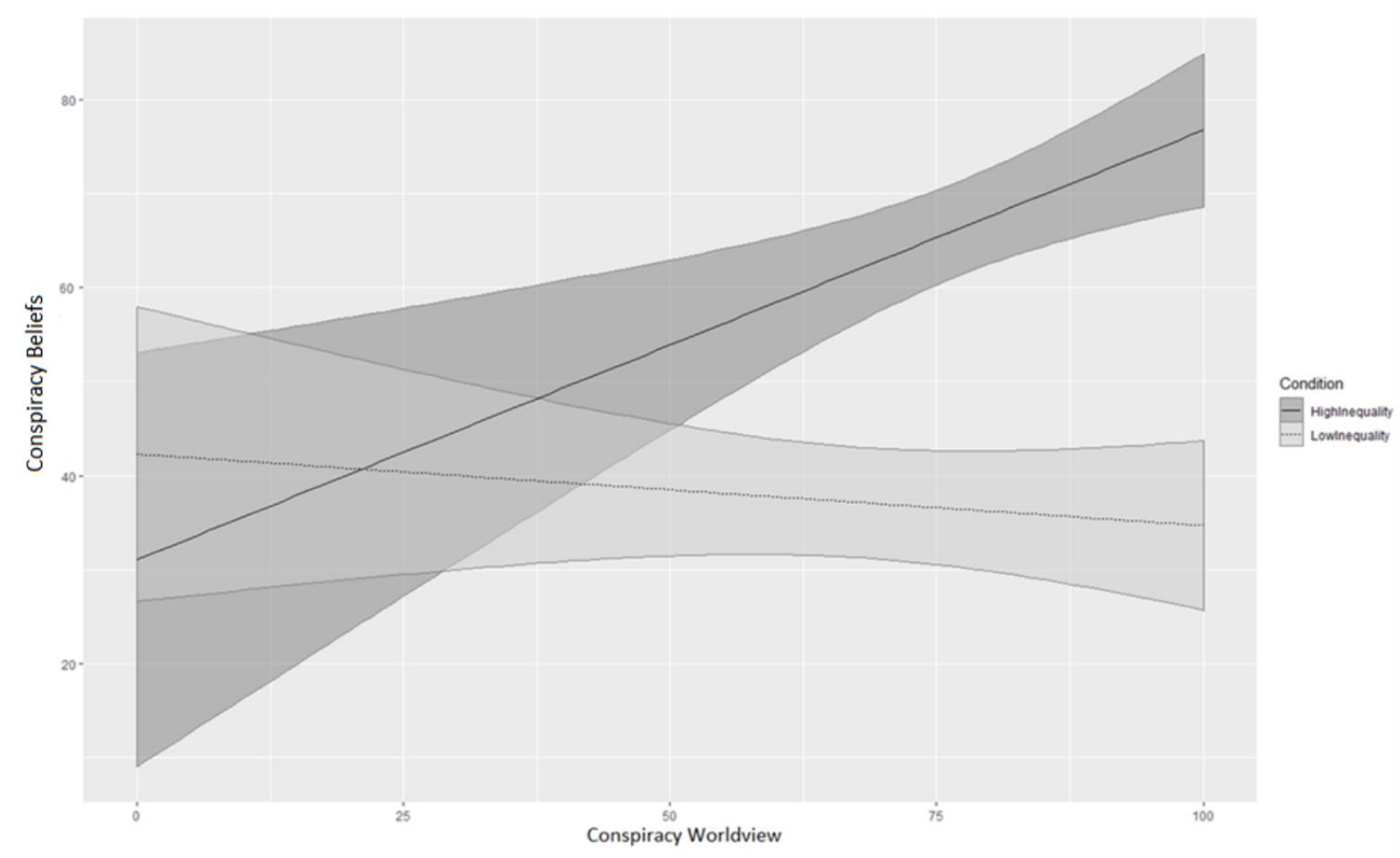

Figure 6. Interaction plot of conspiracy beliefs by conspiracy worldview for high inequality and low inequality conditions.

\section{Situational collective action intentions}

In order to test the effect of our manipulation on the support for collective actions aimed at improving the society of Kalo, we computed a sequence of t-tests, and we corrected the $\mathrm{p}$ values using the Benjamini-Hochberg Procedure (Benjamini \& Hochberg, 1995). Results showed that high (vs. low) inequality condition enhanced collective actions support. This effect was evident only for welfare policies, but not for charity initiatives, or tax compliance (see Table 1 for descriptive and t-test statistics). 
Table 1

Descriptive statistics and independent samples t-tests across the experimental conditions for situational collective action intentions.

\begin{tabular}{|c|c|c|c|c|c|}
\hline & Condition & Mean & SD & $t$ & P value \\
\hline \multirow{2}{*}{$\begin{array}{l}\text { Welfare } \\
\text { policies }\end{array}$} & $\begin{array}{c}\text { High } \\
\text { inequality }\end{array}$ & 71.96 & 15.44 & \multirow{2}{*}{5.374} & \multirow{2}{*}{$<.001$} \\
\hline & $\begin{array}{c}\text { Low } \\
\text { inequality }\end{array}$ & 53.30 & 18.32 & & \\
\hline \multirow{2}{*}{ Charity } & $\begin{array}{c}\text { High } \\
\text { inequality }\end{array}$ & 61.62 & 29.12 & \multirow{2}{*}{1.206} & \multirow{2}{*}{.31} \\
\hline & $\begin{array}{c}\text { Low } \\
\text { inequality }\end{array}$ & 54.53 & 27.04 & & \\
\hline \multirow{2}{*}{ Tax compliance } & $\begin{array}{c}\text { High } \\
\text { inequality }\end{array}$ & 43.96 & 22.65 & \multirow{2}{*}{-1.023} & \multirow{2}{*}{.31} \\
\hline & $\begin{array}{c}\text { Low } \\
\text { inequality }\end{array}$ & 48.66 & 21.44 & & \\
\hline
\end{tabular}

Next, we ran three mediation models, using the same procedure as used in our previous studies. Conspiracy beliefs partially mediated the effect of experimental conditions on collective action intentions aimed at supporting welfare policies (indirect effect: $b=.31, S E=.14, C I=$ $[.04, .63], p=.03$; total effect: $b=.98, S E=.18, C I=[.61,1.35], p<.001$; direct effect: $b=.68$, $S E=.22, C I=[.24,1.09], p=.002$; see Figure 7), but no indirect effects were found for collective action intentions aimed at supporting charity initiatives or taxes (all $p \mathrm{~s}>.05$ ). Overall, H3a was partially supported.

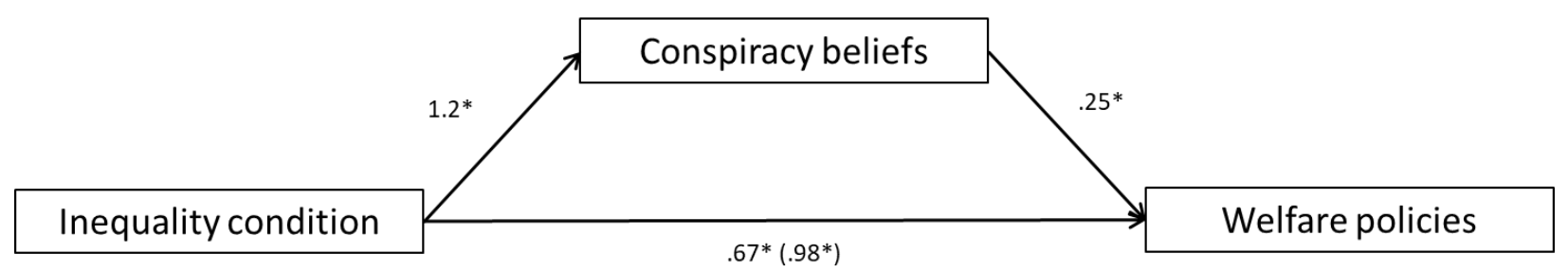

Figure 7. Path model for collective actions supporting Kalo's welfare policies.

\section{General collective action intentions}


The effect of conspiracy beliefs on behavioral intentions toward economic inequalities was not limited to the Kalo scenario. Indeed, in line with H3b, the conspiracy worldview measure was associated with general collective action intentions aimed at reducing economic inequalities $(r=.34, p<.001)$ but was not associated with intentions aimed at reducing gender inequalities $(r=.14, p=.17)$, or illegal immigration $(r=.11, p=.30)$.

\section{Discussion}

Study $4 \mathrm{~b}$ confirms the results of Studies $3 \mathrm{a}, 3 \mathrm{~b}$ and $4 \mathrm{a}$, further corroborating that those participants who envisaged their life in a highly (vs. low) unequal society were more likely to endorse conspiracy beliefs in that society (H1). Overall, the results of Study $4 \mathrm{~b}$ successfully replicated results of Study $4 \mathrm{a}$ by showing that participants more likely to hold a conspiracy worldview were more sensitive to our economic inequality manipulation (H3).

The support for collective actions was different between conditions only in the case of welfare policies. This difference was mediated by conspiracy beliefs. Arguably, economic inequality prompts collective actions aimed at changing the social system, whereas actions related to tax policies and charity initiatives do not directly tackle economic differences (for example, taxes may not be used for redistributing resources).

Importantly, the experimental results were corroborated by the relationship found between conspiracy worldview and general collective actions aimed at reducing economic inequality (H4b). Indeed, a conspiracy worldview was positively associated with behavioral intentions aimed at reducing economic inequalities, providing evidence for the positive outcomes of conspiracy endorsement in terms of challenging the system. This effect appears to be specific to economic inequality, as conspiracy worldview was not associated with a propensity toward collective actions for issues related to gender inequality or illegal immigration. 


\section{General Discussion}

The correlational studies showed a reliable association between actual (Study 1a, 1b, and 1c) and perceived (Study 2) economic inequality and conspiracy beliefs. Moreover, the experimental studies showed a reliable and strong causal effect of our manipulations of economic inequality on conspiracy beliefs. In fact, the perception of economic inequality was consistently associated with conspiracy beliefs across all studies. Previous literature showed that conspiracy beliefs arise in situations characterized by anomie, a feature that is part of a social reality perceived as economically unequal (e.g., Elgar, 2010; Fritsche \& Jugert, 2017; Harding \& Sibley, 2013; Sánchez-Rodríguez et al., 2019; Sprong et al., 2019). As expected, anomie mediated the effect of our manipulations on conspiracy beliefs.

It is also important to consider whether economic inequality triggers the endorsement of general or more specific conspiracy beliefs. Data from Studies 3a and 3b showed that the manipulation of economic inequality affects the endorsement of a wide range of conspiracy beliefs - general conspiracy beliefs as well as conspiracies that relate to the specific fictional society. In Studies $4 \mathrm{a}$ and $4 \mathrm{~b}$, we found that inequality enhanced the belief in conspiracies perpetrated by different groups in the specific fictional society (i.e., politicians, scientists, multinational companies, and pharmaceutical industries) while it did not affect participants' conspiracy worldview. Future research should focus on the impact of economic inequality on the endorsement of specific versus more general conspiracy theories. It may well be the case that the relation between economic inequality and conspiracy belief endorsement is stronger when participants consider specific conspiracy beliefs that blame an outgroup for heightened anomie that results from economic inequality. Such conspiracy beliefs best serve the function of 
mobilizing collective ingroup action that might hold the promise of providing people with a sense of collective agency (or control; see Bukowski et al., 2017).

These results have important implications. First, those who are prone to believe in conspiracy theories are sometimes viewed as driven by irrationality — a vision that is indeed supported by a vast literature about the negative consequences of conspiracy beliefs (e.g., Jolley \& Douglas, 2014; Lewandowsky et al., 2013; Van der Linden, 2015). Other findings show that conspiracy beliefs are associated with dispositional constructs that are prodromal of mental disease, such as schizotypy and delusional thinking (Barron et al., 2018; Darwin et al., 2011). However, factors that trigger conspiracy beliefs are not always irrational and they may be driven by anomie-prompted socio-structural perceptions about societies, such as economic inequality. Developing an understanding of how important psychological needs of people holding conspiracy beliefs are elicited or frustrated by the broader socio-structural context may provide new insights into the ways in which the spread of conspiracy theories can be countered. Such approaches should focus not only on debunking conspiracy theories, but also on the implementation of policies that try to address problems associated with the socio-structural context that triggers them and that undermines social well-being (Cichocka, 2020).

Overcoming the general focus in the psychological literature on the negative outcomes of conspiracy beliefs, the present research contributes a broader perspective on the topic, by stressing the functional byproducts of this attitudinal set. Specifically, we provide evidence that conspiracy beliefs can prompt collective action intentions and engagement.

\section{Limitations and Future Research}

In these studies, we used a fictional scenario that provided us some advantages, such as the fact that the assumptions made by participants in relation to the society are only based on 
how the economic scenario was described, not confounded by other factors. However, even if the experimental settings were necessary to test the direction of effects and to control for potential confounding factors, they are limited in their ecological validity. However, this gap is filled by the correlational evidence from Study 1a, $1 \mathrm{~b}$ and 1c, which showed that objective economic inequality as captured by the Gini coefficient is associated with conspiracy beliefs. These country-level results were corroborated in Study 2, where the perception of economic inequality in Australia was positively associated with conspiracy beliefs.

Another limitation relates to the lack of a control condition in our experiments, making it impossible to determine whether effects are due to the low or the high economic inequality condition. However, we decided against a control condition because it is unclear what a meaningful control would be in the paradigms that we used (i.e., by mentioning inequality, expectations about the level of inequality are made salient). Future research should consider ways to address this issue by testing predictions in other paradigms and settings.

Furthermore, the finding that conspiracy beliefs are the result of the interaction between conspiracy worldview and the economic inequality-related cues provided by the experimental manipulation is in line with the adaptive-conspiracism hypothesis formulated by van Prooijen and van Vugt (2018). However, even though these findings are interesting, its underpinning evolutionary framework cannot be confirmed here, as we did not test the antecedent of conspiracy worldview. Furthermore, the impact of economic inequality on conspiracy beliefs may not be influenced only by conspiracy worldview, and it is possible that one's position in the social ladder may play a role. In particular, participants with lower socio-economic status may be particularly sensitive to the perception of economic inequality. Furthermore, we found no evidence that socio-economic status moderated the relationship between economic inequality and 
the endorsements of conspiracy beliefs thus failing to provide support that this relationship differs for members of different social classes. Further research should explore whether this nulleffect is due to specifics of our samples (e.g., restricted range in terms of social class) or whether it is also found when examining support for this idea in more representative samples.

Even though we provided initial evidence for the anomie-mediation hypothesis in studies $2,3 a$ and $3 b$, this evidence was only correlational. Thus, future research in which anomie is experimentally manipulated is necessary to further corroborate this hypothesis.

We further propose that the perception of permeability of boundaries between economic groups may affect the link between economic inequality and conspiracy beliefs. Specifically, the higher the perception that low-class individuals can engage in upward mobility the easier it is to justify inequality, and this may reduce the need to explain the status quo relying on conspiracy narratives. These predictions should be tested in future research.

Finally, we provide initial evidence for the association between conspiracy beliefs and activism. Here we argue that previous evidence about lack of civic engagement does not exclude a potential link between conspiracy beliefs and activism, as activism may take the form of disobedience, rejection of guidelines provided by authorities, and boycott of products, in other words, organized deliberate inaction. Indeed, here we found an association between conspiracy beliefs and intention to engage in collective action aimed at implementing welfare policies, but not that contributes to taxation or charity initiatives. Further studies are required to both replicate these findings and detect the potential mechanisms.

More specifically, the research about the processes underlying the association between conspiracy beliefs and collective action is only slowly emerging, and future research should focus on the way in which conspiracy beliefs, similar to other ideological beliefs (Ditto \& 
Mastronarde, 2009), trigger collective action. In particular, further research is needed to uncover the dynamics through which conspiracy beliefs may facilitate loyalty to the ingroup which subsequently enhances willingness to engage in collective action.

Finally, it is important to clarify the generalizability of the finding that conspiracy beliefs enhance collective action intentions. Indeed, here we focused only on conspiracy beliefs targeting powerful actors. It is not clear whether economic inequality can prompt conspiracy beliefs targeting less powerful actors (Nera et al., 2021). It may well be that, while conspiracy beliefs targeting powerful actors can result from anomie, conspiracy beliefs targeting less powerful actors might be more associated with conservative ideology, and they may lead to justification of the economic system rather than any challenging of it.

\section{Conclusion}

Future efforts are required to increase our understanding of the conditions that influence the direction and the size of conspiracy belief effects on social behaviors. In this endeavor and despite their highlighted limitations, our studies are an important starting point for understanding how conspiracy beliefs connect to socio-structural features of society. Our studies showed that the perception of economic inequality is a conspiracy-prompting cue for individuals holding a conspiracy worldview, and that conspiracy beliefs are associated with the intention to reduce economic inequality. These results help to explain the relationship between economic inequality and conspiracy beliefs and provide further evidence of the detrimental effects of economic inequality in modern societies. Our results suggest that the building of more equal societies is one way in which we can tackle the spread of misinformation and conspiracy theories.

\section{Data availability statement}


The data related to the analyzed measures are available at:

https://osf.io/vbz2w/?view_only=7277439e36334fc59cc5c94ccd362428 


\section{References}

Abalakina-Paap, M., Stephan, W. G., Craig, T., \& Gregory, W. L. (1999). Beliefs in conspiracies. Political Psychology, 20(3), 637-647. https://www.jstor.org/stable/3792165

Adam-Troian, J., Wagner-Egger, P., Motyl, M., Arciszewski, T., Imhoff, R., Zimmer, F., Klein, O., Babinska, M., Bangerter, A., Bilewicz, M., Blanuša, N., Bovan, K., Bužarovska, R., Cichocka, A., Çelebi, E., Delouvée, S., Douglas, K. M., Dyrendal, A., Gjoneska, B., ... van Prooijen, J. W. (2020). Investigating the links between cultural values and belief in conspiracy theories: The key roles of collectivism and masculinity. Political Psychology, 43(4), 597-618. https://doi.org/10.1111/pops.12716

Adler, N. E., Epel, E. S., Castellazzo, G., \& Ickovics, J. R. (2000). Relationship of subjective and objective social status with psychological and physiological functioning: Preliminary data in healthy, White women. Health psychology, 19(6), 586. https://doi.org/10.1037//02786133.19.6.586.

Albarracin, D., \& Shavitt, S. (2018). Attitudes and attitude change. In Annual Review of Psychology, 69, 299-327. https://doi.org/10.1146/annurev-psych-122216-011911

Benjamini, Y., \& Hochberg, Y. (1995). Controlling the False Discovery Rate: A practical and powerful approach to multiple testing. Journal of the Royal Statistical Society: Series B (Methodological), 57(1), 289-300. https://doi.org/10.1111/j.2517-6161.1995.tb02031.x

Bjarnason, T. (2009). Anomie among european adolescents: Conceptual and empirical clarification of a multilevel sociological concept. Sociological Forum. 24(1), 135-161. https://doi.org/10.1111/j.1573-7861.2008.01089.x

Brennen, J. S., Simon, F., Howard, P. N., \& Nielsen, R. K. (2020). Types, sources, and claims of COVID-19 misinformation. Reuters Institute, 7(3), 1.

Brotherton, R., French, C. C., \& Pickering, A. D. (2013). Measuring belief in conspiracy theories: The generic conspiracist beliefs scale. Frontiers in Psychology, 4. https://doi.org/10.3389/fpsyg.2013.00279 
Bruder, M., Haffke, P., Neave, N., Nouripanah, N., \& Imhoff, R. (2013). Measuring individual differences in generic beliefs in conspiracy theories across cultures: Conspiracy Mentality Questionnaire. Frontiers in Psychology, 4. https://doi.org/10.3389/fpsyg.2013.00225

Bukowski, M., de Lemus, S., Rodriguez-Bailón, R., \& Willis, G. B. (2017). Who’s to blame? Causal attributions of the economic crisis and personal control. Group Processes and Intergroup Relations, 20(6), 909-923. https://doi.org/10.1177/1368430216638529

Clark, C. J., Liu, B. S., Winegard, B. M., \& Ditto, P. H. (2019). Tribalism is human nature. Current Directions in Psychological Science, 28(6), 587-592. https://doi.org/10.1177/0963721419862289

Clarke, S. (2002). Conspiracy theories and conspiracy theorizing. Philosophy of the Social Sciences, 32(2), 131-150. https://doi.org/10.1177/004931032002001

Coffey, C., Espinoza Revollo, P., Harvey, R., Lawson, M., Parvez Butt, A., Piaget, K., ... Thekkudan, J. (2020). Time to Care: Unpaid and underpaid care work and the global inequality crisis. doi:10.21201/2020.5419

Dagnall, N., Drinkwater, K., Parker, A., Denovan, A., \& Parton, M. (2015). Conspiracy theory and cognitive style: A worldview. Frontiers in Psychology, 6. https://doi.org/10.3389/fpsyg.2015.00206

Diamond, S. (1996). Right-wing politics and the anti-immigration cause. Social Justice. $23(3$ (65), 154-168.

Ditto, P. H., \& Mastronarde, A. J. (2009). The paradox of the political maverick. Journal of Experimental Social Psychology, 45(1), 295-298. https://doi.org/10.1016/j.jesp.2008.10.002

Dobson, C., Powers, E. A., Keith, P. M., \& Goudy, W. J. (1979). Anomia, self-esteem, and life satisfaction: Interrelationships among three scales of well-being. Journals of Gerontology, 34(4), 569-572. https://doi.org/10.1093/geronj/34.4.569

Douglas, K. M., Sutton, R. M., \& Cichocka, A. (2017). The psychology of conspiracy theories. Current Directions in Psychological Science, 26(6), 538-542. https://doi.org/10.1177/0963721417718261 
Douglas, K. M., Uscinski, J. E., Sutton, R. M., Cichocka, A., Nefes, T., Ang, C. S., \& Deravi, F. (2019). Understanding conspiracy theories. Political Psychology, 40(S1), 3-35. https://doi.org/10.1111/pops.12568

Durkheim, E. (1987). Suicide (Spaulding, J. A., Simpson, G., Trans.). London, England: Routledge \& Kegan Paul. (Original work published 1897)

Einstein, K. L., \& Glick, D. M. (2015). Do I think BLS data are BS? The Consequences of Conspiracy Theories. Political Behavior, 37(3). https://doi.org/10.1007/s11109-014-9287-z

Elgar, F. J. (2010). Income inequality, trust, and population health in 33 countries, 100(11), 2311-2315. American Journal of Public Health. https://doi.org/10.2105/AJPH.2009.189134

Fay, B. (2019). The nazi conspiracy theory: German fantasies and jewish power in the Third Reich, 35(2), 75-97. Library and Information History. https://doi.org/10.1080/17583489.2019.1632574

Fischer, C. S. (1973). On urban alienations and anomie: powerlessness and social isolation. American Sociological Review, 38(3), 311. https://doi.org/10.2307/2094355

Franko, W. W. (2016). Political context, government redistribution, and the public's response to growing economic inequality, 78(4), 957-973. Journal of Politics. https://doi.org/10.1086/686025

Fritsche, I., Jonas, E., Ablasser, C., Beyer, M., Kuban, J., Manger, A. M., \& Schultz, M. (2013). The power of we: Evidence for group-based control. Journal of Experimental Social Psychology, 49(1), 19-32. https://doi.org/10.1016/j.jesp.2012.07.014

Fritsche, I., \& Jugert, P. (2017). The consequences of economic threat for motivated social cognition and action, 18, 31-36. In Current Opinion in Psychology. https://doi.org/10.1016/j.copsyc.2017.07.027

Fritsche, I., Moya, M., Bukowski, M., Jugert, P., de Lemus, S., Decker, O., ... \& NavarroCarrillo, G. (2017). The great recession and group-based control: Converting personal helplessness into social class in-group trust and collective action. Journal of Social Issues, 73(1), 117-137. doi: 10.1111/josi.12207 
Harding, J. F., \& Sibley, C. G. (2013). The palliative function of system justification: Concurrent benefits versus longer-term costs to wellbeing, 113(1), 401-418. Social Indicators Research. https://doi.org/10.1007/s11205-012-0101-1

Hilbert, R. A. (1986). Anomie and the Moral Regulation of Reality: The Durkheimian Tradition in Modern Relief, 4(1), 1. Sociological Theory. https://doi.org/10.2307/202102

Holland, T. G., Peterson, G. D., \& Gonzalez, A. (2009). A cross-national analysis of how economic inequality predicts biodiversity loss. Conservation Biology, 23(5), 1304-1313. https://doi.org/10.1111/j.1523-1739.2009.01207.x

Hornsey, M. J., Harris, E. A., \& Fielding, K. S. (2018). The psychological roots of antivaccination attitudes: A 24-nation investigation, 37(4), 307-315. Health Psychology. https://doi.org/10.1037/hea0000586

Imhoff, R., Dieterle, L., \& Lamberty, P. (2021). Resolving the puzzle of conspiracy worldview and political activism: belief in secret plots decreases normative but increases nonnormative political engagement, 12(1), 71-79. Social Psychological and Personality Science. https://doi.org/10.1177/1948550619896491

Ionescu, O., Tavani, J. L., \& Collange, J. (2020). Perceived societal anomie, collective memory, and support for collective action: Perceiving that current French society is anomic influences present support for collective action through the reconstructed national past. Asian Journal of Social Psychology, 24(3), 405-420. https://doi.org/10.1111/ajsp.12438

Jolley, D., \& Douglas, K. M. (2014). The social consequences of conspiracism: Exposure to conspiracy theories decreases intentions to engage in politics and to reduce one's carbon footprint, 105(1), 35-56. British Journal of Psychology. https://doi.org/10.1111/bjop.12018

Kata, A. (2010). A postmodern Pandora's box: Anti-vaccination misinformation on the Internet. Vaccine, 28(7), 1709-1716. https://doi.org/10.1016/j.vaccine.2009.12.022

Kim, Y. (2019). How conspiracy theories can stimulate political engagement. Journal of Elections, Public Opinion and Parties, 1-21. https://doi.org/10.1080/17457289.2019.1651321 
Klofstad, C. A., Uscinski, J. E., Connolly, J. M., \& West, J. P. (2019). What drives people to believe in Zika conspiracy theories? Palgrave Communications, 5(1). https://doi.org/10.1057/s41599-019-0243-8

Landau, M. J., Kay, A. C., \& Whitson, J. A. (2015). Compensatory control and the appeal of a structured world. Psychological Bulletin, 141(3), 694. https://doi.org/10.1037/a0038703

Lange, M., \& Monscheuer, O. (2021). Spreading the disease: protest in times of pandemics. SSRN Electronic Journal. https://doi.org/10.2139/ssrn.3787921

Lantian, A., Muller, D., Nurra, C., \& Douglas, K. M. (2016). Measuring belief in conspiracy theories: Validation of a French and English single-item scale, 29(1), 1. International Review of Social Psychology. https://doi.org/10.5334/irsp.8

Levine, T. R., Asada, K. J., \& Carpenter, C. (2009). Sample sizes and effect sizes are negatively correlated in meta-analyses: Evidence and implications of a publication bias against nonsignificant findings. Communication Monographs, 76(3), 286-302. https://doi.org/10.1080/03637750903074685

Love, J., Selker, R., Marsman, M., Jamil, T., Dropmann, D., Verhagen, J., Ly, A., Gronau, Q. F., Šmíra, M., Epskamp, S., Matzke, D., Wild, A., Knight, P., Rouder, J. N., Morey, R. D., \& Wagenmakers, E. J. (2019). JASP: Graphical statistical software for common statistical designs. Journal of Statistical Software, 88(1), 1-17. https://doi.org/10.18637/jss.v088.i02

Miller, S. (2002). Conspiracy theories: Public arguments as coded social critiques: a rhetorical analysis of the twa flight 800 conspiracy theories. Argumentation and Advocacy, 39(1), 4056. https://doi.org/10.1080/00028533.2002.11821576

Mueller, D. C., \& Stratmann, T. (2003). The economic effects of democratic participation. Journal of Public Economics, 87(9-10). https://doi.org/10.1016/S0047-2727(02)00046-4

Nera, K., Wagner-Egger, P., Bertin, P., Douglas, K., \& Klein, O. (2021). A power-challenging theory of society, or a conservative mindset? Upward and downward conspiracy theories as ideologically distinct beliefs. European Journal of Social Psychology. https://doi.org/10.1002/ejsp.2769 
Nishi, A., Shirado, H., Rand, D. G., \& Christakis, N. A. (2015). Inequality and visibility of wealth in experimental social networks. Nature, 526(7573), 426-429. https://doi.org/10.1038/nature15392

Norasakkunkit, V., \& Uchida, Y. (2011). Psychological consequences of postindustrial anomie on self and motivation among Japanese youth. Journal of Social Issues, 67(4), 774786.https://doi.org/10.1111/j.1540-4560.2011.01727.x

OECD (2011). Divided we stand: Why inequality keeps rising. In Divided we stand: Why inequality keeps rising. https://doi.org/10.1787/9789264119536-en

Pickett, K. E., \& Wilkinson, R. G. (2015). Income inequality and health: A causal review. In Social Science and Medicine, 128, 316-326. https://doi.org/10.1016/j.socscimed.2014.12.031

Pietraszewski, D., Curry, O. S., Petersen, M. B., Cosmides, L., \& Tooby, J. (2015). Constituents of political cognition: Race, party politics, and the alliance detection system. Cognition, 140, 24-39. https://doi.org/10.1016/j.cognition.2015.03.007

Piketty, T. (2018). Capital in the 21st Century. In Inequality in the 21st Century. https://doi.org/10.4324/9780429499821-9

Preacher, K. J., \& Hayes, A. F. (2008). Asymptotic and resampling strategies for assessing and comparing indirect effects in multiple mediator models. Behavior Research Methods, 40(3), 879-891. https://doi.org/10.3758/BRM.40.3.879

Samory, M., \& Mitra, T. (2018). Conspiracies online: User discussions in a conspiracy community following dramatic events. 12th International AAAI Conference on Web and Social Media, ICWSM 2018.

Sánchez-Rodríguez, Á., Willis, G. B., Jetten, J., \& Rodríguez-Bailón, R. (2019). Economic inequality enhances inferences that the normative climate is individualistic and competitive. European Journal of Social Psychology, 49(6), 1114-1127. https://doi.org/10.1002/ejsp. 2557

Solt, F., Habel, P., \& Grant, J. T. (2011). Economic Inequality, Relative Power, and Religiosity. 
Social Science Quarterly, 92(2), 447-465. https://doi.org/10.1111/j.15406237.2011.00777.x

Sprong, S., Jetten, J., Wang, Z., Peters, K., Mols, F., Verkuyten, M., Bastian, B., Ariyanto, A., Autin, F., Ayub, N., Badea, C., Besta, T., Butera, F., Costa-Lopes, R., Cui, L., Fantini, C., Finchilescu, G., Gaertner, L., Gollwitzer, M., ... Wohl, M. J. A. (2019). “Our country needs a strong leader right now": Economic inequality enhances the wish for a strong leader. Psychological Science, 30(11), 1625-1637. https://doi.org/10.1177/0956797619875472

Stojanov, A., \& Halberstadt, J. (2020). Does lack of control lead to conspiracy beliefs? A metaanalysis. European Journal of Social Psychology, 50(5), 955-968. https://doi.org/10.1002/ejsp.2690

Swami, V. (2012). Social psychological origins of conspiracy theories: The case of the Jewish conspiracy theory in Malaysia. Frontiers in Psychology, 3. doi:10.3389/fpsyg.2012.00280

Swami, V., \& Coles, R. (2010). The truth is out there: belief in conspiracy theories. The Psychologist. 23(7), 560-563.

Teymoori, A., Bastian, B., \& Jetten, J. (2017). Towards a psychological analysis of anomie. Political Psychology, 38(6), 1009-1023. https://doi.org/10.1111/pops.12377

Thorlindsson, T., \& Bernburg, J. G. (2004). Durkheim's theory of social order and deviance: A multi-level test. In European Sociological Review. 20(4), 271-285. https://doi.org/10.1093/esr/jch025

Uscinski, J. E., Douglas, K., \& Lewandowsky, S. (2017). Climate change conspiracy theories. In Oxford Research Encyclopedia of Climate Science. https://doi.org/10.1093/acrefore/9780190228620.013.328

Uscinski, J. E., Klofstad, C., \& Atkinson, M. D. (2016). What drives conspiratorial beliefs? The role of informational cues and predispositions. Political Research Quarterly, 69(1), 5771.https://doi.org/10.1177/1065912915621621

van Prooijen, J. W., \& Acker, M. (2015). The influence of control on belief in conspiracy theories: Conceptual and applied extensions. Applied Cognitive Psychology, 29(5), 753- 
761.https://doi.org/10.1002/acp.3161

van Prooijen, J. W., \& Douglas, K. M. (2017). Conspiracy theories as part of history: The role of societal crisis situations. Memory Studies, 10(3), 323-333.

https://doi.org/10.1177/1750698017701615

van Prooijen, J. W., \& van Vugt, M. (2018). Conspiracy theories: Evolved functions and psychological mechanisms. Perspectives on Psychological Science, 13(6), 770-788. https://doi.org/10.1177/1745691618774270

van Zomeren, M., Spears, R., \& Leach, C. W. (2010). Experimental evidence for a dual pathway model analysis of coping with the climate crisis. Journal of Environmental Psychology, 30(4), 339-346. https://doi.org/10.1016/j.jenvp.2010.02.006

Walker, R. S., \& Bailey, D. H. (2013). Body counts in lowland South American violence. Evolution and Human Behavior, 34(1), 29-34. https://doi.org/10.1016/j.evolhumbehav.2012.08.003

West, H. G., \& Sanders, T. (2003). Transparency and conspiracy: Ethnographies of suspicion in the New World Order. Durham, NC: Duke University Press. https://doi:10.2307/j.ctv11smwft

Wilkinson, R. G., \& Pickett, K. E. (2017). The enemy between us: The psychological and social costs of inequality. European Journal of Social Psychology, 47(1), 11-24. https://doi.org/10.1002/ejsp.2275

Wood, M. J., Douglas, K. M., \& Sutton, R. M. (2012). Dead and alive: Beliefs in contradictory conspiracy theories. Social Psychological and Personality Science, 3(6), 767-773. https://doi.org/10.1177/1948550611434786

Zonis, M., \& Joseph, C. M. (1994). Conspiracy thinking in the Middle East. Political Psychology, 15(3), 443-459. https://doi.org/10.2307/3791566 